\title{
HAPLODIPLOIDY IN PHARYNGODONID (OXYUROIDEA : NEMATODA) PARASITES OF TESTUDO GRAECA.
}

\author{
M. L. ADAMSON and A. J. PETTER*
}

SUMMARY. Gametogenesis is described in Tachygonetria conica, T. dentata, T. macrolaimus, T. numidica, T. longicollis longicollis, T. l. pusilla, T. l. setosa, Mehdiella uncinata and M. microstoma, parasites of Testudo graeca from Tunisia. All species reproduced by haplodiploidy (males developed from unfertilized eggs and were haploid and females developed from fertilized eggs and were diploid). Metaphase of oogonial divisions contained ten rod-shaped chromosomes and meiosis in females resulted in two polar bodies and an egg pronucleus. Embryos in eggs in utero contained either five or ten chromosomes depending presumably on whether or not they developed from fertilized ova. Metaphase of spermatogonial divisions contained five rod-shaped chromosomes but divisions just anterior to the seminal vesicle contained five short round chromosomes similar to meiotic chromosomes but consisting of only two chromatids. Males of haplodiploid species have no homologous chromosomes and it is suggested that meiosis during spermatogenesis, rather than being replaced by mitosis as previously suggested (Adamson, 1981), simply begins at the second meiotic division.

\section{Haplodiploïdie chez les Pharyngodonidae (Oxyuroidea : Nematoda) parasites de Testudo graeca}

RÉSUMÉ. La gametogenèse est décrite chez les espèces Tachygonetria conica, T. dentata, T. macrolaimus, T. numidica, T. longicollis longicollis, T. l. pusilla, T. l. setosa, Mehdiella uncinata et M. microstoma, parasites d'une Testudo graeca tunisienne. Toutes ces espèces se reproduisent par haplodiploidie (les mâles sont issus d'œufs non fécondés et sont haploïdes et les femelles sont issues d'œufs fécondés et sont diploïdes). Les figures de métaphase dans les oogonies montrent 10 chromosomes en bâtonnets et la méiose chez les femelles aboutit à la formation de 2 globules polaires et un pronucleus. Les œufs dans l'utérus contiennent des embryons soit à 10 soit à 5 chromosomes vraisemblablement suivant qu'ils sont issus d'œufs fécondés ou non fécondés. Les figures de métaphase dans les spermatogonies montrent 5 chromosomes en bâtonnets mais les figures de divisions dans la zone immédiatement antérieure à la vésicule séminale montrent 5 chromosomes courts et ronds semblables aux chromosomes de la méiose, mais constitués de seulement 2 chromatides. Les mâles des espèces haplodiploïdes n'ont pas de chromosomes homologues et il est suggéré que la méiose au cours de la spermatogenèse, au lieu d'être remplacée par une mitose comme cela avait été supposé précédemment (Adamson, 1981), commence simplement à la $2^{\mathrm{e}}$ division méiotique.

* Laboratoire des Vers, associé au C.N.R.S., Muséum National d'Histoire Naturelle, 61 rue Buffon, F 75231 Paris Cedex 05.

Accepté le 3 novembre I982. 


\section{Introduction}

Individual Testudo graeca in north Africa may be infected with up to a dozen species of oxyuroid nematodes (Petter, 1966). During a study of chromosome numbers in these species it was observed that at least some of them reproduced by haplodiploidy, i.e., males develop from unfertilized eggs and are haploid whereas females develop from fertilized eggs and are diploid. This form of reproduction has been reported only once before in nematodes (Adamson, 1981), in another oxyuroid, Gyrinicola batrachiensis (Walton, 1929). A preliminary note has already been published (Adamson and Petter 1982) and the present communication gives details on gametogenesis in species parasitizing Testudo in north Africa.

\section{Materials and methods}

Nematodes collected from the faeces of a single specimen of Testudo graeca from Tunisia were identified using a dissecting or compound microscope. Adult males and females were placed in a drop of $0.5 \% \mathrm{NaCl}$ on a microscope slide; the reproductive tract was dissected out and the rest of the worm discarded. The slide was flooded with fixative $(6 \%$ formaldehyde in a solution of three parts ethanol to one part acetic acid) and immersed in a coplin jar containing fresh fixative. Slides were held overnight in fixative at $-20^{\circ} \mathrm{C}$ before being stained.

A drop of stain (2\% haematoxylin in a $50 \%$ solution of proprionic acid) was placed over the specimen. An iron needle was introduced into the drop and slowly moved back and forth until the stain became a rich brown. The stained specimen was squashed beneath a coverslip and the preparation was ringed with nail polish.

\section{Results}

The following species were collected: Tachygonetria conica, T. dentata, T. macrolaimus, T. numidica, T. longicollis pusilla, T. longicollis setosa, T. longicollis longicollis, Mehdiella uncinata, and $M$. microstoma. All species apparently reproduced by haplodiploidy and gametogenesis was similar in all. Data were most complete for $T$. conica, $T$. dentata, $T$. macrolaimus and $T$. mumidica and the following description is based on observations of $T$. conica.

Male

Three zones were recognized in the testis: 1) Germinative zone: beginning at the blind end of the testis and characterized by spermatogonia with large interphase nuclei containing faintly staining filamentous nuclear material. Mitoses contained five chromosomes; chromosomes were long and thread-like in early prophase but condensed to short rods with smooth outlines in metaphase (fig. $1 \mathrm{~B}$ ). 


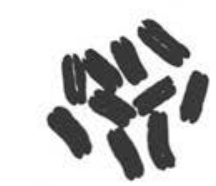

$\mathbf{a}$

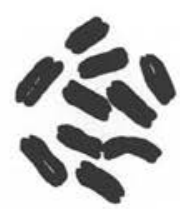

b

A

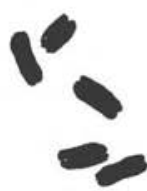

a

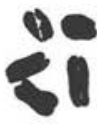

b

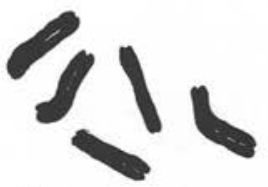

c
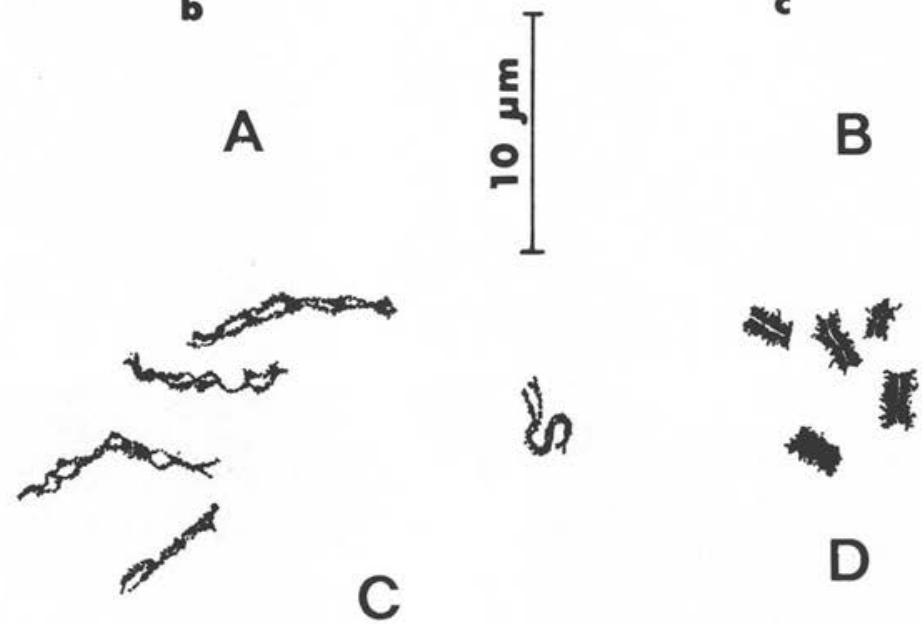

D

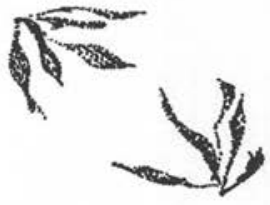

E

Fig. I. - Chromosomes of Tachygonetria conica. A, chromosomes from 2 metaphase plates from germinative zone of ovary. B, chromosomes from three metaphase plates from germinative zone of testis. C to E, divisions in zone just before seminal vesicle of testis: C, prophase; D, metaphase; E, telophase. 
2) Growth zone: distal to germinative zone and characterized by spermatocytes with small densely staining interphase nuclei. Mitoses were rare in this zone.

3) Transformation zone: just before seminal vesicle characterized by many dividing cells. Chromosomes in this zone condensed to form short rods with fuzzy outlines (fig. $1 C, D$ and $2 A$ ). During anaphase, two groups of five chromosomes were formed;
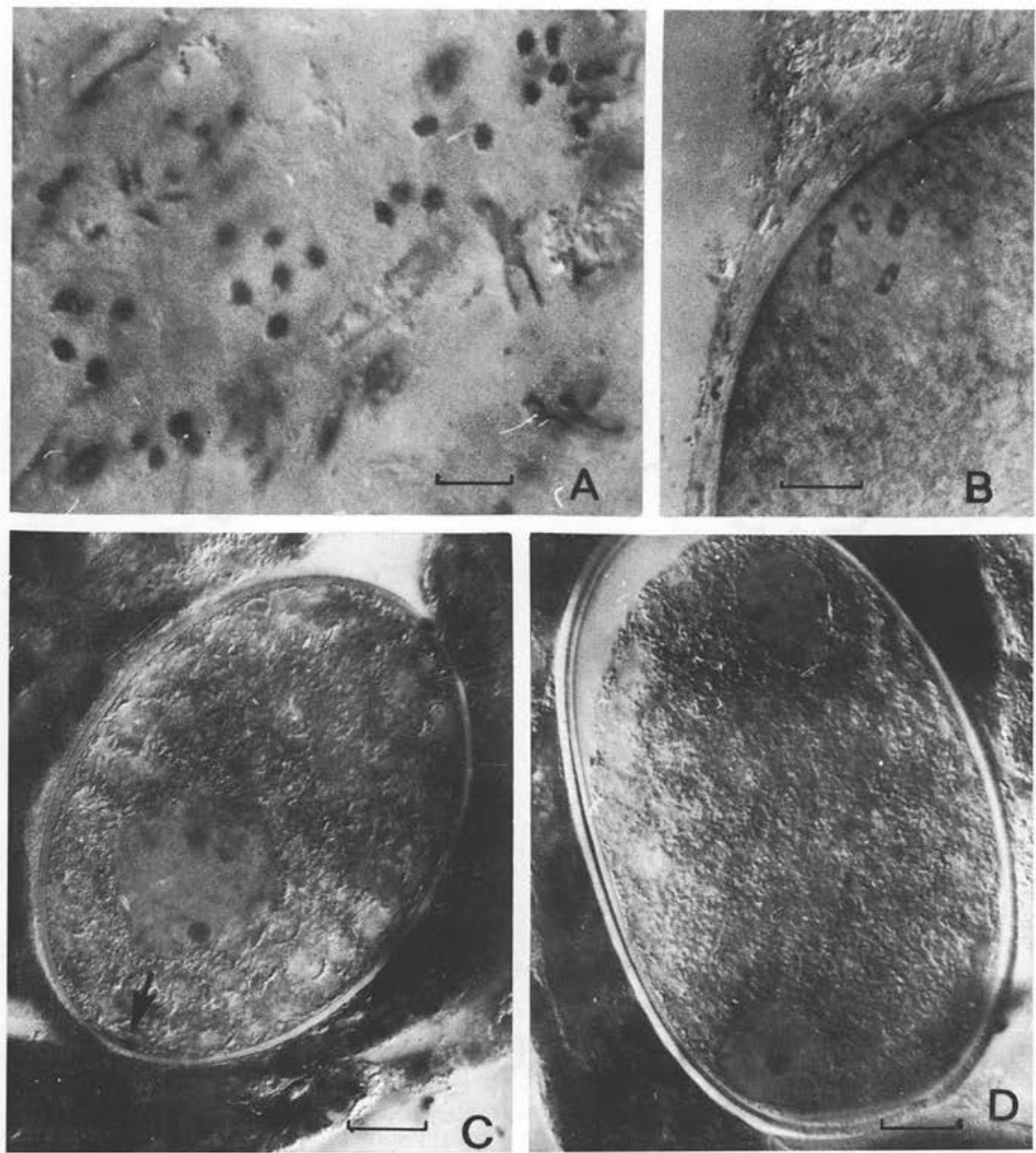

FIG. 2. - A, metaphase figures from zone of testis of Tachygonetria conica just before seminal vesicle. B, bivalents in ovum of $T$. conica. C, ovum of $T$. dentata (presumably unfertilized) showing one pronucleus. Note second polar body (arrow) has been given off and shell formation is underway. D, ovum from same individual of $T$. dentata (presumably fertilized) showing two pronucléi. (scale bar for $\mathrm{A}=5 \mu \mathrm{m} ; \mathrm{B}$ to $\mathrm{D}$ scale bar $=10 \mu \mathrm{m}$ ). 
chromosomes in each group formed a five-pointed star-like formation ( $\mathrm{fig} .1 \mathrm{E}$ ) which apparently condensed to form the "tail" of the spermatozoa at the end of the division.

Female

The ovary was divided into a short germinative and long growth zone.

Interphase nuclei in the germinative zone were similar to those observed in the male with faintly staining filamentous nuclear material. Mitoses in this region contained ten chromosomes which were short and rod-like at metaphase (fig. $1 \mathrm{~A}$ ).

Between germinative and growth zones, chromosomes condensed to form tight, darkly staining clusters. Chromosomes gradually separated at the beginning of the growth zone; they were visibly double stranded and oriented with their free ends to one pole of the nucleus. Chromosomes further down the growth zone became more dispersed, stained more faintly and were associated with a large faintly staining nucleoli. Mature oocytes contained a large sherical nucleus with a prominent nucleolus and faintly staining filamentous nuclear material.

In the oviduct and upper uterus, chromosomes condensed to form five bivalents each consisting of two pairs of chromosomes (homologous pairs) attached end to end (fig. $2 \mathrm{~B}$ ). In some ova a small densely staining sperm nucleus was observed but other ova were apparently unfertilized.

Bivalents divided to form the first polar body which separated from the egg cytoplasm and was visible as a circle of five chromosome pairs on the inside of the egg shell during early cleavage. The second meiotic division gave rise to a second polar body which remained in the egg cytoplasm; the five remaining maternal chromosomes presumably formed the egg pronucleus but pronuclear stages were not observed in this species.

Embryos in eggs developed to the morula stage in ovo. Mitotic divisions in these embryos contained either five or ten chromosomes depending on the embryo examined and many females contained embryos of both types.

Observations on species other than $T$. conica

Embryos of $T$. dentata did not develop as far in utero as did those of $T$. conica. Many eggs in various stages of meiosis were observed and this was similar to that in $T$. conica. In addition, many pronuclear stages were observed. These contained either one or two pronuclei presumably depending on whether or not they had been fertilized (fig. $2 C$ and D).

Chromosomes were not observed in males of Mehdiella microstoma and M. uncinata. However, meiosis was absent in spermatogenesis and oogenesis in females was similar to that observed in $T$. conica. Embryos with five as well as those with ten chromosomes were present in the uterus of individual females.

Males were observed in only one subspecies of $T$. longicollis (i.e. T. l. longicollis); there were five chromosomes and meiosis was absent. Oogenesis in all subspecies was similar to that in $T$. conica and embryos with five as well as those with ten chromosomes were observed in the uteri of individual females. 


\section{Discussion}

Haplodiploidy (also referred to as male parthenogenesis or arrhenotoky) has probably arisen on relatively few occasions in evolution (White, 1973). Aside from the oxyuroid nematodes, this form of reproduction is known in monogonant rotifers, certain acarines, and thysanopteran, hymenopteran, homopteran and coleopteran insects. It tends to operate among groups of closely related species and some haplodiploid taxa have become highly successful (Oliver, 1971).

The distribution of haplodiploidy in the order Oxyurida needs further investigation. None of the Thelastomatidae have been investigated. Species investigated here belong to the Pharyngodonidae and the only other member of this family examined, Gyrinicola batrachiensis, also reproduces by haplodiploidy (Adamson, 1981); males have four chromosomes and females eight.

Three members of the Oxyuridae have been investigated but the data are unclear. Meves (1920) claimed there were three or four chromosomes in spermatocytes of Passalurus ambiguus but it is unclear from his description whether or not meiosis occurs in the testis. The two meiotic divisions are illustrated in ova and there appear to be three bivalents. Walton (1924) listed the diploid number of chromosomes as seven in males and eight in females and then in 1959, listed it as four. In both articles he cited Meves (1920) as authority and this species should be reinvestigated.

Walton (1924) described a diploid number of fifteen chromosomes in males and sixteen in females of Syphacia obvelata. This indicates that sex determination in his material was by an $\mathrm{XX} / \mathrm{XO}$ mechanism. However, preliminary studies on $S$. obvelata infecting mice in the animal house of the Laboratoire des Vers (Muséum national d'Histoire naturelle) indicate that these worms are haplodiploid; males have four and females eight chromosomes (personal observations).

Goswami (1976 A and B, 1977) claimed that sex determination in Aspiculuris kazakstanica, the only member of the Heteroxynematinae (Oxyuridae) investigated, was of the XX/XO type. Males have eleven and female twelve chromosomes.

White (1973) noted that in haplodiploid species, meiosis must be altered in males to avoid the further reduction of their haploid chromosome complement and Hartl and Brown (1970) listed this as one of the possible barriers to the origin of haplodiploidy. It was suggested previously (Adamson, 1981), that in males of G. batrachiensis meiosis is replaced by a single mitotic division. However, in the present study chromosomes in the transformation zone of the testis (the zone where meiosis would normally occur) differed from those observed in mitoses in the germinative zone or in cleavage divisions. They were more condensed and had fuzzy outlines and in this respect resembled meiotic chromosomes.

Meiosis in females (after replication of chromosomes) began by pairing of homologous chromosomes which separated during the first meiotic division (reduction division). In males there are no homologous chromosomes (they are hemizygous) 
and perhaps meoisis is taken up at the second meiotic division. This would explain morphological differences between chromosomes in the transformation zone and those elsewhere in the body. Furthermore, if this was true, modification of meiosis in haploid males, rather than requiring complicated changes, might be a simple consequence of the haploid condition.

\section{BIBLIOGRAPHY}

Adamson M. L.: Studies on gametogenesis in Gyrinicola batrachiensis (Walton, 1929) (Oxyuroidea; Nematoda). Can. J. Zool., I981, s9, r368-1376.

Adamson M. L., Petter A. J.: Evidence of haplodiploidy in pharyngodonid (Nematoda; Oxyuroidea) parasites of Testudo graeca. Ann. Parasitol. Hum. Comp., 1982, 57, 197.

Goswami U.: Chromosomal studies during cleavage divisions in ten species of nematodes. Res. Bull. (Sci.) Panjab. Univ., 1976a, 27, 119-120.

Goswamr U.: Chromosomes during fertilization in nematodes. Res. Bull. (Sci.) Panjab. Univ., 1976b, 27, 21 7-218.

Goswami U.: Karyological studies on fifteen species of parasitic nematodes. Res. Bull. (Sci.) Panjab. Univ., 1977, 28, III-II2.

HARTL D. L., BRown S. W.: The origin of male haploid genetic systems and their expected sex ratios. Theoret Pop. Biol., 1970, 1, 165-190.

Meves F.: Ueber Samenbildung und Befruchtung bei Oxyuris ambigua. Arch. Mikrosk. Anat., 1920, $94,135-184$.

Petrer A. J.: Équilibre des espèces dans les populations de nématodes parasites du colon des tortues terrestres. Mem. Mus. Natl. Hist. Nat., 1966, 39, I-252.

Oliver J. H.: Parthenogenesis in mites and ticks (Äcari). Am. Zool., I971, II, 283-29I.

Walton A. C.: Studies on nematode gametogenesis. Z. Zellforsch. Mikrosk. Anat., 1924, I, 167239.

Walton A. C.: Some parasites and their chromosomes. J. Parasitol., I959, 45, I-20.

White M. J. D.: Animal cytology and evolution. Third edition, 961 p. Cambridge University Press, Cambridge, I973. 